\title{
Calcium intake and risk of fracture: systematic review
}

\author{
Mark J Bolland, 'William Leung, ${ }^{2}$ Vicky Tai, ${ }^{1}$ Sonja Bastin, ${ }^{3}$ Greg D Gamble, ${ }^{1}$ Andrew Grey, ${ }^{1}$ Ian R Reid
}

\section{ABSTRACT}

OBJECTIVE

To examine the evidence underpinning recommendations to increase calcium intake through dietary sources or calcium supplements to prevent fractures.

\section{DESIGN}

Systematic review of randomised controlled trials and observational studies of calcium intake with fracture as an endpoint. Results from trials were pooled with random effects meta-analyses.

\section{DATA SOURCES}

Ovid Medline, Embase, PubMed, and references from relevant systematic reviews. Initial searches undertaken in July 2013 and updated in September 2014.

\section{ELIGIBILITY CRITERIA FOR SELECTING STUDIES} Randomised controlled trials or cohort studies of dietary calcium, milk or dairy intake, or calcium supplements (with or without vitamin D) with fracture as an outcome and participants aged $>50$.

RESULTS

There were only two eligible randomised controlled trials of dietary sources of calcium $(n=262)$, but 50 reports from 44 cohort studies of relations between dietary calcium $(n=37)$, milk $(n=14)$, or dairy intake $(n=8)$ and fracture outcomes. For dietary calcium, most studies reported no association between calcium intake and fracture (14/22 for total, 17/21 for hip, 7/8 for vertebral, and $5 / 7$ for forearm fracture). For milk $(25 / 28)$ and dairy intake (11/13), most studies also reported no associations. In 26 randomised controlled trials, calcium supplements reduced the risk of total fracture (20 studies, $n=58573$; relative risk $0.89,95 \%$ confidence interval 0.81 to 0.96 ) and vertebral fracture (12 studies, $n=48967.0 .86,0.74$ to 1.00 ) but not hip (13 studies, $n=56648 ; 0.95,0.76$ to 1.18 ) or forearm fracture (eight studies, $n=51775 ; 0.96,0.85$ to 1.09 ).

\section{WHAT IS ALREADY KNOWN ON THIS TOPIC}

Older men and women are recommended to take at least $1000-1200 \mathrm{mg} /$ day of calcium to prevent fractures, and many people take calcium supplements to meet these recommendations

Recent trials have raised concerns about the safety of calcium supplements Experts have therefore encouraged older people to increase their calcium intake through food rather than by taking supplements, but it is not known whether increasing dietary calcium intake prevents fractures

\section{WHAT THIS STUDY ADDS}

Dietary calcium intake is not associated with risk of fracture, and there is currently no evidence that increasing calcium intake prevents fractures

Calcium supplements have small inconsistent benefits on fracture prevention

Increasing calcium intake, through calcium supplements or dietary sources, should not be recommended for fracture prevention
Funnel plot inspection and Egger's regression suggested bias toward calcium supplements in the published data. In randomised controlled trials at lowest risk of bias (four studies, $n=44505$ ), there was no effect on risk of fracture at any site. Results were similar for trials of calcium monotherapy and co-administered calcium and vitamin D. Only one trial in frail elderly women in residential care with low dietary calcium intake and vitamin D concentrations showed significant reductions in risk of fracture.

\section{CONCLUSIONS}

Dietary calcium intake is not associated with risk of fracture, and there is no clinical trial evidence that increasing calcium intake from dietary sources prevents fractures. Evidence that calcium supplements prevent fractures is weak and inconsistent.

\section{Introduction}

Older men and women are recommended to take at least 1000-1200 mg/day of calcium for bone health and prevention of fractures. ${ }^{1}$ The average intake in the diet in Western countries is 700-900 mg/day, and lower in Asia and Africa, meaning that most older people would need to take calcium supplements to meet these recommendations. These guidelines for calcium intake have been widely implemented, and, in some Western countries, more than $30-50 \%$ of older women take calcium supplements. ${ }^{2-5}$ Clinical trials of calcium supplements at doses of $1000 \mathrm{mg} /$ day, however, have reported adverse effects, including cardiovascular events, ${ }^{6-8}$ kidney stones, ${ }^{9}$ and hospital admissions for acute gastrointestinal symptoms. ${ }^{10}$ Consequently, older people have been encouraged to improve bone health by increasing their calcium intake through food rather than by taking supplements. ${ }^{11}$ This advice assumes that increasing dietary calcium intake to the recommended level of $>1200 \mathrm{mg} /$ day prevents fractures without causing the adverse effects of calcium supplements.

We assessed the evidence supporting the recommendation to increase dietary calcium intake to prevent fractures and compared the anti-fracture efficacy of increasing calcium intake through dietary sources with the anti-fracture efficacy of calcium supplements. We undertook a systematic review of studies of dietary sources of calcium or calcium supplements in older adults ( $>50)$ with fracture as an endpoint. We primarily focused on the results of randomised controlled trials, but when insufficient evidence from such trials was available, we considered results of observational studies.

\section{Methods}

\section{Literature search}

In July 2013, we searched Ovid Medline and Embase since inception for English language studies of calcium, milk, or dairy intake, or calcium supplements 
that reported on a broad range of skeletal and nonskeletal endpoints including fracture. The full text of the search was designed with assistance from a professional librarian and is shown in appendix 1 . From this search, we also identified 120 systematic reviews or meta-analyses on these topics and hand searched these articles, any other articles included in our review, and recent review articles on fracture risk for other relevant articles. In September 2014, we updated the results with a focused search (no language restrictions) of PubMed (appendix 1) and Embase for studies with fracture or bone mineral density as an endpoint.

\section{Study selection}

We included randomised controlled trials and cohort, case-control, or cross sectional studies with fracture as an outcome in which participants were aged $>50$ at baseline, or for cohort studies, where most follow-up occurred in participants aged $>50$. We excluded studies where most participants had a major systemic pathology at baseline other than osteoporosis, such as renal failure or malignancy. We included studies of calcium supplements used in combination with other treatment provided that the other treatment was given to both arms (for example, calcium plus oestrogen $v$ placebo plus oestrogen), and included studies of co-administered calcium and vitamin D supplements (CaD). We classified milk, dairy products, and dietary calcium intake from food as dietary sources of calcium. We treated hydroxyapatite as a dietary source of calcium, though it is not a food because hydroxyapatite supplements are made from bone and contain other minerals, hormones, protein, and amino acids in addition to calcium. Several cohort studies reported analyses of calcium intake and fracture risk in more than one publication. We included the results from the publication that reported the longest duration of follow-up for the cohort. Superseded publications are listed in appendix 1. Titles and abstracts were screened by one author (WL or MJB) and the full text of potentially relevant studies reviewed by two authors independently (WL, MJB, VT, or SB). The flow of articles is shown in appendix 2.

\section{Data extraction}

From each study we extracted information on characteristics of participants, study design, funding source and conflicts of interest, and numbers of participants with total, hip, forearm, and vertebral fractures. When data were reported for non-vertebral fracture but not total fracture, we treated non-vertebral fractures as total fractures. A single author (WL, MJB, or VT) extracted data, which were checked by a second author (MJB or SB). Risk of bias was assessed as recommended in the Cochrane Handbook, ${ }^{12}$ and we planned a subgroup analysis for each fracture outcome stratified by risk of bias. Any discrepancies were resolved through discussion.

\section{Incorporation of studies}

In one randomised controlled trial ${ }^{13}$ it was not clear whether the data reported were total number of fractures or number of participants with a fracture. Another was described as a cluster trial of three different fracture prevention programmes: $\mathrm{CaD}$, an environmental programme, or both. ${ }^{14}$ Treatment was randomly assigned to each cluster, however, which was based on location of residence and there were only four clusters (one cluster per treatment group), so in effect participants were quasi-randomised by location. The $\mathrm{CaD}$ and environmental programmes included an intervention-a home visit by a nurse to review treatment-which was not offered to the control group. Thus, the best estimate of the effect of $\mathrm{CaD}$ in the study is a comparison of both programmes (CaD and environmental) with the environmental programme, whereas the comparison of $\mathrm{CaD}$ versus no $\mathrm{CaD}$ assesses a multifactorial intervention. For these reasons, we considered these two randomised controlled trials to be at high risk of bias and included them only in sensitivity analyses. One trial was described in the methods as a cluster randomised controlled trials but was analysed as individually randomised. ${ }^{1516}$ We analysed the trial as a cluster trial in the primary analyses, using the approach recommended in the Cochrane handbook ${ }^{12}$ with an intracluster correlation coefficient of $0.023^{1718}$ and an estimated average cluster size of 3.5. In sensitivity analyses we analysed the trial as individually randomised. In one trial $^{9}$ there was an interaction between oestrogen treatment, $\mathrm{CaD}$ treatment, and risk of hip fracture. ${ }^{19}$ In women taking oestrogen, CaD reduced risk of hip fracture (relative risk 0.59, 95\% confidence interval 0.38 to 0.93 ), whereas in women not taking oestrogen, CaD had no effect on risk (1.20, 0.85 to 1.69$).{ }^{19}$ We included the data for all participants in the trial in the primary analyses but used results of participants not taking oestrogen from this reanalysis in sensitivity analyses.

\section{Statistics}

For randomised controlled trials, data were pooled with random effects meta-analyses and heterogeneity was assessed with the $\mathrm{I}^{2}$ statistic $\left(\mathrm{I}^{2}>50 \%\right.$ was considered significant heterogeneity). We used funnel plots and Egger's regression model to assess for bias. For the primary analyses, we assessed the effects of calcium with or without vitamin $\mathrm{D}$, and in subgroup analyses we assessed calcium monotherapy and co-administered CaD separately. Randomised controlled trials of $\mathrm{CaD}$ versus vitamin $\mathrm{D}$, in which the groups differed only in treatment by calcium, were included in subgroup analyses of calcium monotherapy, while trials of CaD versus placebo or controls were included in the CaD subgroup analyses. For trials with factorial designs or more than two arms, in which multiple comparisons can occur, we included all available data from the study. Thus, for factorial randomised controlled trials we included all study arms that allowed a comparison of calcium versus no calcium in the primary analyses and the calcium monotherapy subgroup analysis, but only arms comparing $\mathrm{CaD}$ with controls in the $\mathrm{CaD}$ subgroup analysis. For multi-arm 


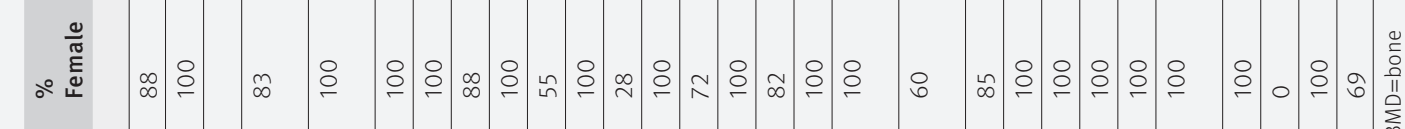

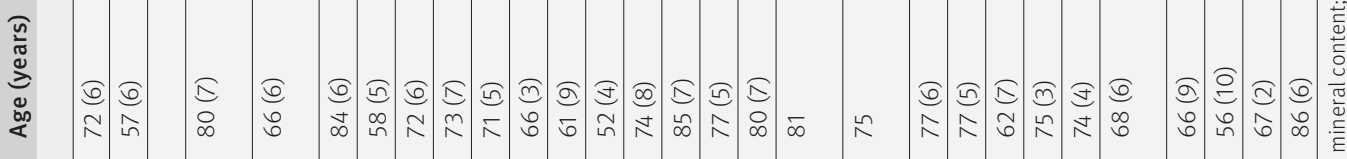

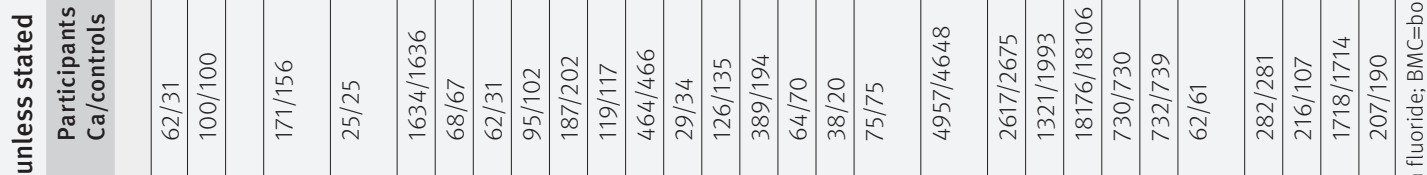

气ิ

草

: $\quad$ 를

Е)

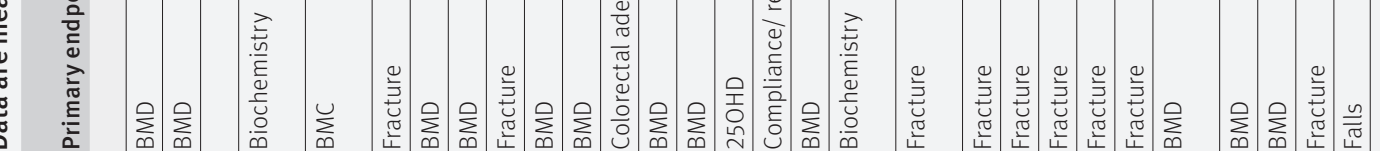

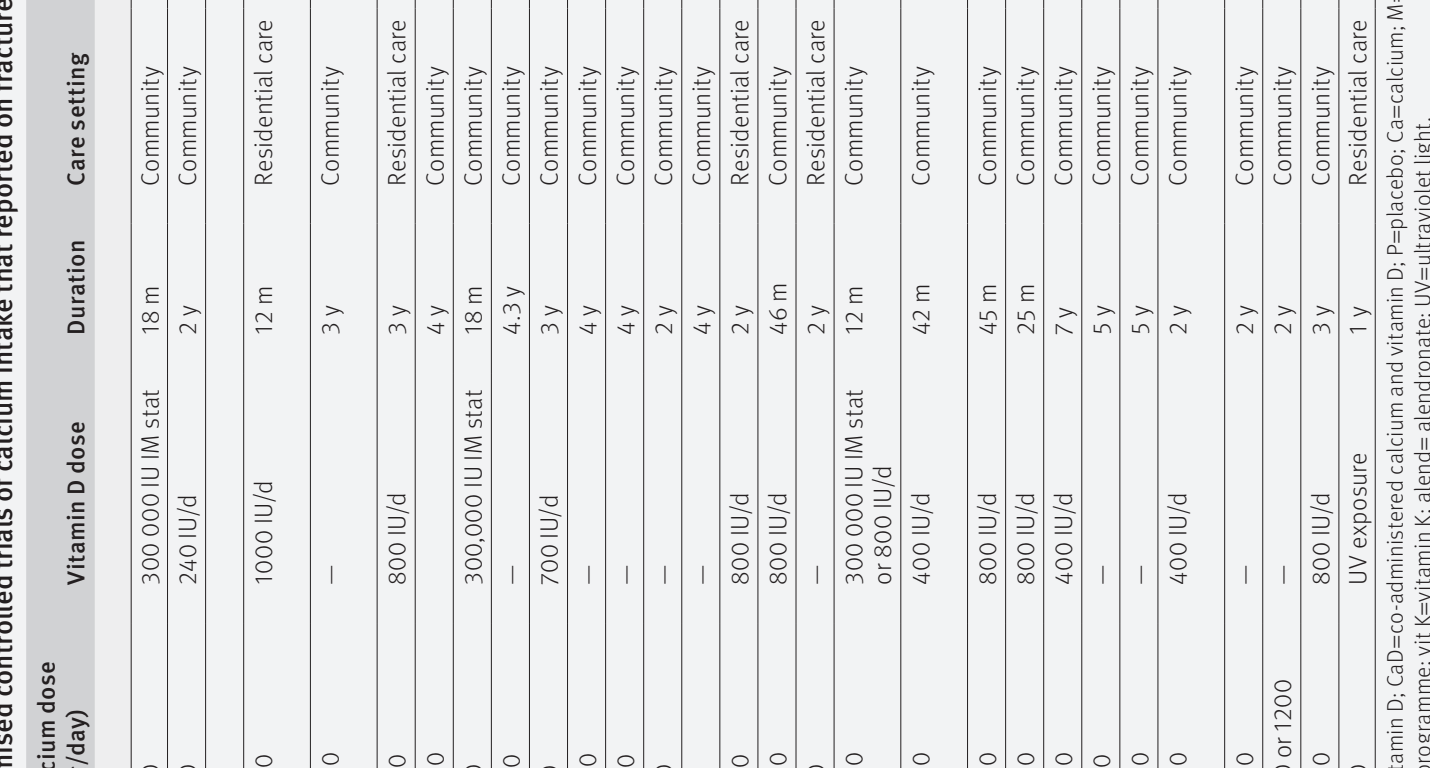

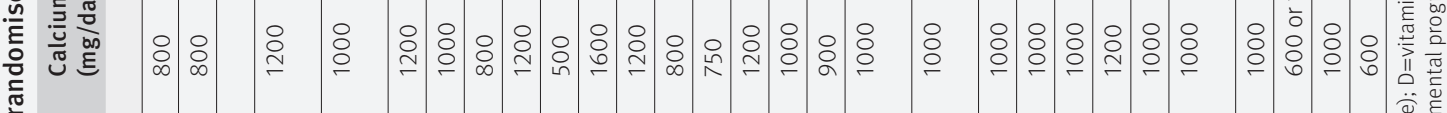

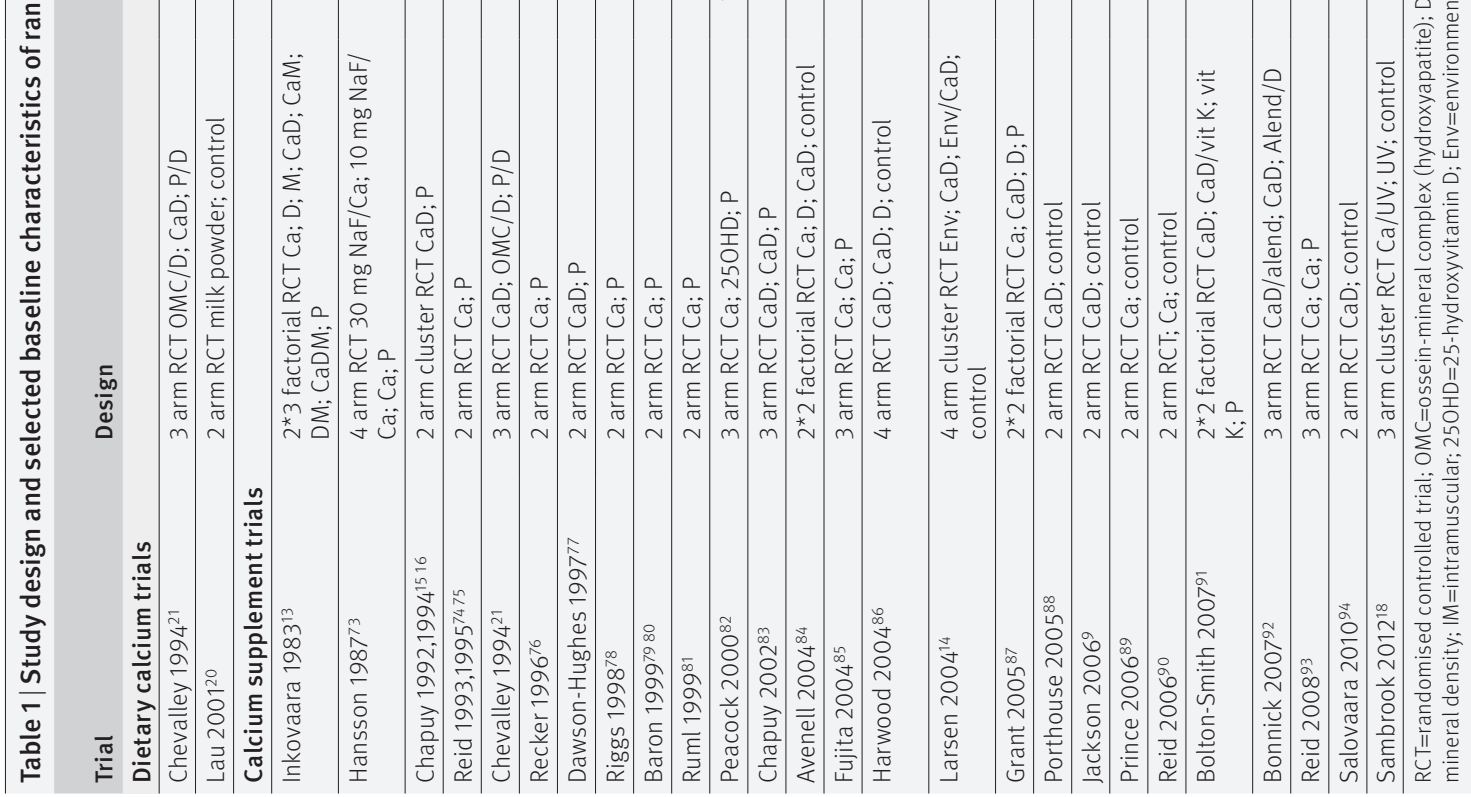


randomised controlled trials, we pooled data from the separate treatment arms for the primary analyses, but each treatment arm was used only once. We undertook analyses of prespecified subgroups (risk of bias, calcium monotherapy versus $\mathrm{CaD}$, participants living in the community versus residential care, and baseline dietary calcium intake $<800 \mathrm{mg} /$ day) with a random effects model and performed a test for interaction between subgroups. Sensitivity analyses were performed to explore the effects of incorporating different study designs and risk of bias. All tests were two tailed and $\mathrm{P}<0.05$ was considered significant. All analyses were performed with Comprehensive Meta-Analysis (Version 2, Biostat, Englewood, NJ, USA).

For prospective cohort studies, authors reported their data in four different ways: the risk of fracture by group with the cohort divided into two to five groups by baseline dietary intake; pooled risk of fracture per unit of dietary intake; mean baseline dietary intake in individuals with or without subsequent fracture; or a written description of any association. We used only one association from each study for each fracture outcome with priority assigned in the order listed. These four different types of data cannot be combined in a meta-analysis and therefore we did not pool the results of different studies. Instead, we assessed whether there was an association between dietary intake and risk of fracture for each study. We classified associations into four groups: no association, inverse association (where a higher intake was associated with a lower risk of fracture, or a lower intake with a higher risk), a positive association (where a higher intake was associated with a higher risk of fracture or a lower intake with a lower risk), or a U shaped association (where both higher and lower intakes were associated with a higher risk of fracture). We considered associations to be present when there were significant differences between mean baseline dietary intakes (assessed by $t$ tests either reported in the paper or calculated post hoc with OpenEpi; www.OpenEpi.com) or when the confidence interval for a group excluded 1 . For studies that reported data from three or more groups of dietary intake, we assessed the results for the group furthest from the reference group. Thus, when the reference group had the lowest dietary intake, we assessed results from the group with the highest intake; when the reference group had the highest dietary intake, we assessed results from the group with the lowest intake; and when the reference group had intermediate dietary intake, we assessed results from the groups with both highest and lowest intake.

\section{Results}

Dietary sources of calcium Randomised controlled trials

We identified two randomised controlled trials of dietary sources of calcium: milk powder in one $(n=200$, calcium dose $800 \mathrm{mg} /$ day, vitamin D dose 240 IU/day) ${ }^{20}$ and a preparation of hydroxyapatite in the other $(n=62$, calcium dose $800 \mathrm{mg} /$ day). ${ }^{21}$ Table 1 and table $\mathrm{A}$ in appendix 3 show the study designs and selected baseline characteristics. For the randomised controlled trial of milk powder, there was one fracture in the milk group and three in the controls (relative risk 0.33, 95\% confidence interval 0.04 to 3.2; $\mathrm{P}=0.34$ ). For the trial of the hydroxyapatite preparation, fracture data were not reported separately for the hydroxyapatite arm $(n=31$ participants) but were reported for the 62 participants receiving hydroxyapatite or calcium supplements and are included in the analyses of calcium supplements.

\section{Cohort studies}

As there were too few randomised controlled trials of dietary calcium intake that reported fracture to draw conclusions, we analysed observational studies. We identified 50 publications ${ }^{22-71}$ from 44 cohort studies reporting relations between dietary calcium $(n=37)$, milk ( $n=14)$, dairy intake $(n=8)$, or calcium supplements $(n=11)$ and fracture outcomes. There were sufficient cohort studies to analyse, so we did not analyse case-control or cross sectional studies, which are considered a lower level of evidence. Table 2 and table $C$ in appendix 3 show the study design and selected characteristics of the cohort studies.

Tables 3-5 and tables E-F in appendix 3 summarise the results of these cohort studies. For dietary calcium, 14/22 studies (32853 with fracture/291273 participants) reported no relation between calcium intake and total fracture (table 3), 17/21 no relation with hip fracture (2629 with fracture/329414 participants) (table 4), 7/8 no relation with vertebral fracture (711 with fracture/54140 participants) (table 5), and 5/7 no relation with forearm fracture (1065 with fracture/65268 participants) (table 5). Thus, 43 of the 58 (74\%) reported associations between dietary calcium intake and fracture outcomes were neutral. When relations were reported, they were usually inverse (13/15 associations), with one study describing a positive relation and one study a $U$ shaped relation. Of these 15 associations, 14 reported a numerical relative risk estimate, and 11 of these 14 estimates were between 0.5 and 2.0, which are considered weak associations in observational studies. ${ }^{72}$ For milk and dairy intake (tables D and E in appendix 3), nearly all studies reported no association with fracture risk, with 25/28 neutral associations for milk intake and fracture risk and 11/13 for dairy intake.

\section{Calcium supplements \\ Randomised controlled trials}

We identified 26 randomised controlled trials ( $n=69107$ participants) of calcium supplements that reported fracture outcomes. ${ }^{913-16182173-94}$ Table 1 and table A in appendix 3 shows the study design and selected baseline characteristics of the randomised controlled trials. Fourteen studied calcium monotherapy, eight studied $\mathrm{CaD}$, and four were multi-arm or factorial studies of both agents. Twenty trials used a dose of $\geq 1000 \mathrm{mg} /$ day of calcium; 21 were in individuals living in the community; 15 had a duration of three or more years; in 16 , the mean age of participants at baseline was $\geq 70$; in 
Table 2 | Study design and selected characteristics of cohort studies reporting fractures. Data are mean (SD) or range unless stated. For dietary calcium, milk, and dairy intake, and calcium supplement, "yes" indicates data reported for this variable in article

\begin{tabular}{|c|c|c|c|c|c|c|c|c|c|c|c|c|}
\hline \multirow[b]{2}{*}{ Author } & \multirow[b]{2}{*}{$\begin{array}{l}\text { No in } \\
\text { group }\end{array}$} & \multirow[b]{2}{*}{$\begin{array}{l}\% \\
\text { Female }\end{array}$} & \multirow[b]{2}{*}{ Duration } & \multirow[b]{2}{*}{$\begin{array}{l}\text { Age } \\
\text { (years) }\end{array}$} & \multirow{2}{*}{$\begin{array}{l}\text { Dietary } \\
\text { calcium } \\
\text { intake }\end{array}$} & \multirow[b]{2}{*}{$\begin{array}{l}\text { Milk } \\
\text { intake }\end{array}$} & \multirow[b]{2}{*}{$\begin{array}{l}\text { Dairy } \\
\text { intake }\end{array}$} & \multirow[b]{2}{*}{$\begin{array}{l}\text { Calcium } \\
\text { supplement }\end{array}$} & \multicolumn{4}{|c|}{ No with fracture } \\
\hline & & & & & & & & & Total & Hip & Vertebra & Forearm \\
\hline Riggs $1982^{22}$ & 72 & 100 & $5 y$ & 64 & - & - & - & Yes & - & - & $107^{*}$ & - \\
\hline Holbrook $1988^{23}$ & 957 & 55 & $14 \mathrm{y}$ & $50-79$ & Yes & - & - & - & - & 33 & - & - \\
\hline Wickham $1989^{24}$ & 1419 & 49 & $15 y$ & $\geq 65$ & Yes & - & - & - & - & 44 & - & - \\
\hline Paganini-Hill $1991^{25}$ & 13649 & NS & $7 y$ & 73 & Yes & - & - & Yes & - & 418 & - & - \\
\hline Looker $1993^{26}$ & $2226 t$ & 100 & $14.6 y$ & $50-74$ & Yes & - & - & - & - & 122 & - & - \\
\hline Huang $1996^{27}$ & $2513+$ & 100 & $13.4 \mathrm{y}$ & $62(9)$ & - & - & Yes & - & - & 130 & - & - \\
\hline Cumming $1997^{28}$ & 9704 & 100 & $6.6 y$ & 72 & Yes & Yes & - & Yes & 1950 & 332 & 389 & 467 \\
\hline Fujiwara $1997^{29}$ & 4573 & 65 & $14 \mathrm{y}$ & 59 (12) & - & Yes & - & - & - & 55 & - & - \\
\hline Meyer $1997^{30}$ & 39787 & 50 & $11.4 \mathrm{y}$ & $47(5)$ & Yes & Yes & - & - & - & 213 & - & - \\
\hline Owusu $1997^{31}$ & 43063 & 0 & $8 y$ & $54(10)$ & Yesł & Yes & - & Yesł & - & 56 & - & 201 \\
\hline Mussolino $1998^{32}$ & $2879+$ & 0 & $22 y$ & 61 & Yes & - & - & - & - & 71 & - & - \\
\hline Munger $1999^{33}$ & 32050 & 100 & $3.3 y$ & $61(4)$ & Yes & Yes & Yes & Yes & - & 44 & - & - \\
\hline Honkanen $2000^{34}$ & $11798 t$ & 100 & $5 y$ & $52(3)$ & Yes & - & - & - & - & - & - & 368 \\
\hline Huopio $2000^{35}$ & $3068 t$ & 100 & $3.6 y$ & 53 & Yes & - & - & - & 257 & - & - & - \\
\hline Kato $2000^{36}$ & 6250 & 100 & $7.6 y$ & 58 & Yes & - & - & - & 1025 & - & - & $193 \S$ \\
\hline Nguyen $2001^{37}$ & $1844 t$ & 60 & $7.6 y$ & $70(7)$ & Yes & - & - & - & - & - & - & 121 \\
\hline Dargent-Molina $2002^{38}$ & 1588 & 100 & $3.7 \mathrm{y}$ & 81 & Yes & - & - & - & - & NS & - & - \\
\hline Albrand $2003^{39}$ & 672 & 100 & $5.3 y$ & 59 & Yes & - & - & & 75 & - & - & - \\
\hline Feskanich $2003^{40}$ & 72337 & 100 & $18 y$ & 60 & Yes & Yes & - & Yes & & 603 & - & - \\
\hline Michaelsson $2003^{41}$ & $60689+$ & 100 & $11 \mathrm{y}$ & 54 & - & Yes & Yes & - & 3986 & 1535 & - & - \\
\hline Melton $2003^{42}$ & 225 & 100 & $14 \mathrm{y}$ & 68 & Yes & - & - & - & 126 & - & - & - \\
\hline Roy $2003^{43}$ & 6575 & 52 & $3.8 \mathrm{y}$ & $63(8)$ & - & Yes & - & - & - & - & 224 & - \\
\hline van def Klift $2004^{44}$ & 3001 & 54 & $6.3 y$ & $66(7)$ & Yes & - & - & - & - & - & 157 & - \\
\hline Kanis $2005^{45}$ & $39563^{\star \star}$ & 69 & $3.8 \mathrm{y}$ & 64 & - & Yes & - & - & 2469 & 413 & - & - \\
\hline Papaioannou $2005^{46}$ & 5143 & 100 & $3 y$ & $63(10)$ & Yesף & - & - & - & 280 & - & 34 & - \\
\hline Cauley $2007^{47}$ & 159579 & 100 & $8 y$ & $63(7)$ & Yesף & - & - & - & 23270 & - & - & - \\
\hline Diez-Perez $2007^{48}$ & 5146 & 100 & $3 y$ & $72(5)$ & Yes & - & - & - & 311 & 49 & - & 104 \\
\hline Key $2007^{49}$ & 34696 & 77 & $5.2 y$ & 47 & Yes & - & - & - & 1898 & - & - & - \\
\hline Kung $2007^{50}$ & 1435 & 100 & $5 y$ & $63(8)$ & Yes & - & - & - & 80 & - & - & - \\
\hline Lewis $2007^{51}$ & 5876 & 0 & $4.1 \mathrm{y}$ & 74 & Yesף & - & - & - & 275 & - & - & - \\
\hline Nguyen $2007^{52}$ & $924 t$ & 100 & $10 y$ & $69(6)$ & Yes & - & - & - & 221 & 24 & 76 & - \\
\hline Van Geel $2007^{53}$ & 2367 & 100 & $10 y$ & $62(7)$ & Yes & - & - & - & 380 & - & - & - \\
\hline Dargent-Molina $2008^{54}$ & 36217 & 100 & $8.4 \mathrm{y}$ & $56(6)$ & Yes & - & - & Yes & 2408 & - & - & - \\
\hline Meier $2008^{55}$ & $609+$ & 0 & $5.8 \mathrm{y}$ & $73(6)$ & Yes & - & - & - & 113 & 27 & 55 & - \\
\hline Nieves $2008^{56}$ & 52144 & 100 & $3.3 y$ & 65 & Yes & - & - & - & 2205 & 337 & - & - \\
\hline Koh $2009^{57}$ & 63154 & 56 & $7.1 \mathrm{y}$ & 56 & Yesף & - & - & Yes & - & 968 & - & - \\
\hline Nakamura $2009^{58}$ & 75879 & 54 & $10 y$ & $52(8)$ & Yes & Yes & - & - & - & - & 364 & - \\
\hline Thomas-John $2009^{59}$ & 257 & 0 & $3 y$ & $77(4)$ & - & - & Yes & Yes & 41 & - & - & - \\
\hline Gronskag $2010^{60}$ & 4851 & 100 & $9.3 y$ & 73 & - & Yes & - & - & - & 391 & - & - \\
\hline Benetou $2011^{61}$ & 29122 & 64 & $8 y$ & 64 & Yes & - & Yes & - & - & 275 & - & - \\
\hline Nakamura $2011^{62}$ & 773 & 100 & $5.5 \mathrm{y}$ & $75(4)$ & Yes & - & - & - & 51 & - & - & - \\
\hline Warensjo $2011^{63}$ & $61433 t$ & 100 & $19 y$ & 54 & Yes & - & - & - & 14738 & 3871 & - & - \\
\hline Khan $2012^{64}$ & 12528 & NS & $13-14 y$ & $45-64$ & Yes & - & - & - & 824 & - & - & - \\
\hline Rouzi $2012^{65}$ & 707 & 100 & $5.2 y$ & $61(7)$ & Yes & - & - & - & 138 & - & - & - \\
\hline Feart $2013^{66}$ & $1482 \dagger$ & 63 & $8 y$ & $76(5)$ & - & Yes & Yes & - & 155 & 57 & 43 & 73 \\
\hline Prentice $2013^{67}$ & 46892 & 100 & $7.2 y$ & $50-79$ & - & - & - & Yes & 6640 & 451 & - & - \\
\hline Samieri $2013^{68}$ & $1482+$ & 63 & $8 y$ & $76(5)$ & Yes & - & - & Yes & 155 & - & - & - \\
\hline Sahni $2013^{69}$ & 3212 & 56 & $12 y$ & $55(10)$ & - & Yes & Yes & - & - & 43 & - & - \\
\hline Domiciano $2014^{70}$ & 707 & 64 & $4.3 y$ & $73(5)$ & - & - & Yes & - & - & - & 111 & - \\
\hline Sahni $2014^{71}$ & 764 & NS & $11.6 \mathrm{y}$ & $77(5)$ & - & Yes & - & - & - & 97 & - & - \\
\hline $\begin{array}{l}\text { NS =not stated, IF=funding } \\
{ }^{*} \text { Data are number of verteb } \\
\text { tReports from same cohort } \\
\text { fReported total calcium int } \\
\text { §Data for forearm and hip f } \\
\text { १Reported total calcium int } \\
\text { **Individual patient meta-a }\end{array}$ & $\begin{array}{l}\text { y grants from } \\
\text { al fractures n } \\
\text { studies. Repo } \\
\text { ke divided in } \\
\text { acture not rep } \\
\text { ke only. Trea }\end{array}$ & $\begin{array}{l}\text { depende } \\
\text { number } \\
\text { with long } \\
\text { dairy and } \\
\text { ted sepa }\end{array}$ & $\begin{array}{l}\text { unders; Ind= } \\
\text { irticipants } w \\
\text { duration of } f \\
\text { 1-dairy intak } \\
\text { ly; includes }\end{array}$ & $\begin{array}{l}\text { ded by gr } \\
\text { vertebral } \\
\text { ow-up and }\end{array}$ & $\begin{array}{l}\text { is from inc } \\
\text { ctures. } \\
\text { most nun }\end{array}$ & $\begin{array}{l}\text { iry and/o } \\
\text { rof fract } \\
\text { d as diet }\end{array}$ & $\begin{array}{l}\text { by indu } \\
\text { for each } \\
\text { ntake, ar }\end{array}$ & $\begin{array}{l}\text { iation incl } \\
\text {-dairy inta }\end{array}$ & ate & ment & ium intake. & \\
\hline
\end{tabular}




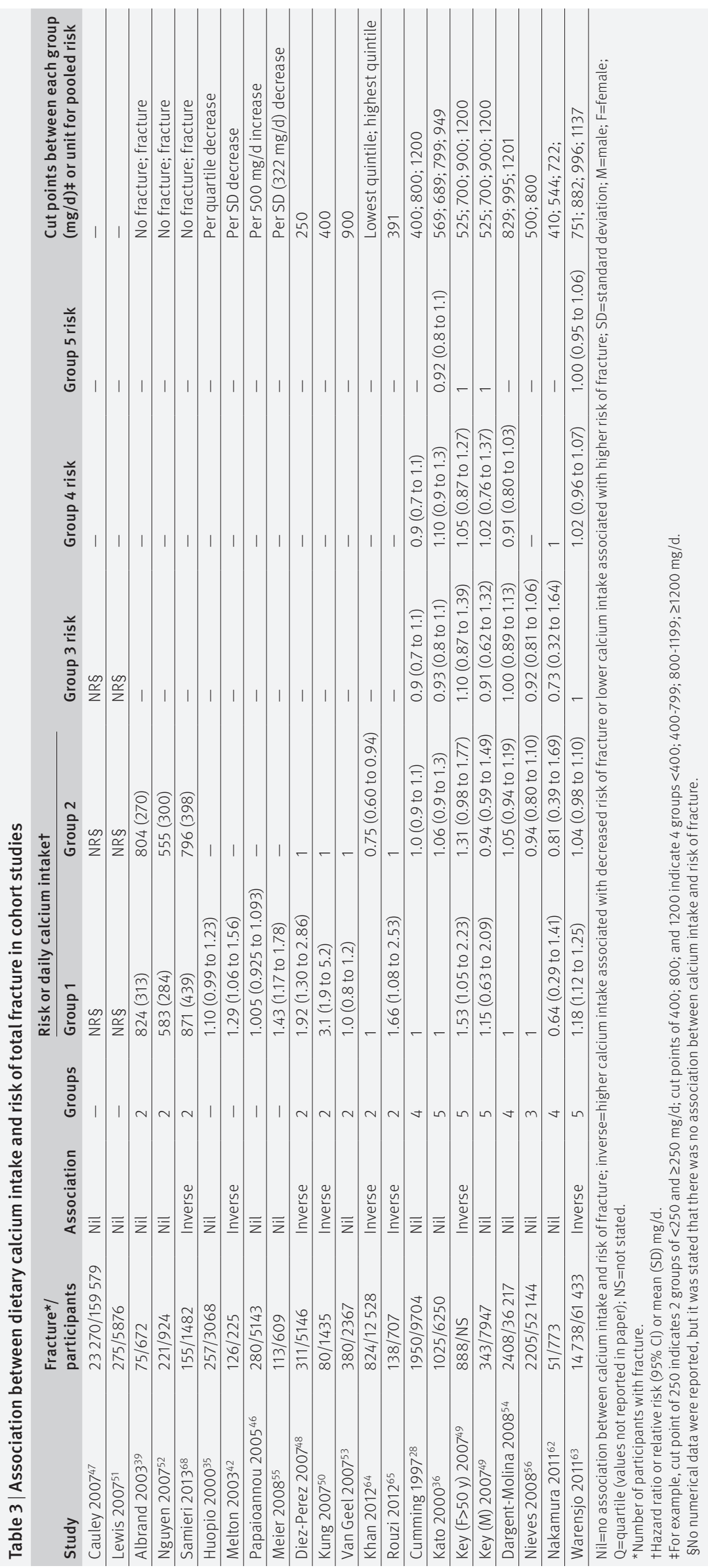

24 most participants were women; and in 10 of 19 randomised controlled trials that reported baseline dietary calcium intake, the level was $<800 \mathrm{mg} /$ day. Table B in appendix 3 shows our assessment of the risk of bias: three trials were assessed as low risk of bias, one as high risk of bias for hip fracture but low risk for other outcomes, nine as moderate risk of bias, and 13 as high risk of bias.

Figures 1-4 show that calcium supplements reduced the risk of total fracture ( 20 studies, $\mathrm{n}=58573$; relative risk 0.89 , 95\% confidence interval 0.81 to 0.96 ; $\mathrm{P}=0.004$; fig 1 ) and vertebral fracture (12 studies, $\mathrm{n}=48967$; 0.86, 0.74 to 1.00 ; $\mathrm{P}=0.04$; fig 3 ) but not hip fracture (13 studies, $\mathrm{n}=56648 ; 0.95,0.76$ to 1.18 ; $\mathrm{P}=0.63$; fig 2) or forearm fracture (eight studies, $\mathrm{n}=51775 ; 0.96,0.85$ to 1.09; $\mathrm{P}=0.54$; fig 4 ). With Egger's regression model and visual inspection of funnel plots, data seemed biased toward reduction in risk with calcium supplements for total $(\mathrm{P}=0.006)$, vertebral $(\mathrm{P}=0.002)$, and forearm fracture $(\mathrm{P}=0.06)$, raising the possibility of publication bias. Furthermore, the pooled effect estimates for all fracture outcomes seemed related to the risk of bias. Figures 1, 3 and 4 and table 2 show that the effect size was smallest and not significant for total, forearm, and vertebral fracture in the subgroup of studies at lowest risk of bias, and that results also differed by risk of bias for hip fracture (fig 2).

Table 6 shows the results of the prespecified subgroup analyses. There was no evidence of a difference in the results between the subgroups of calcium monotherapy or $\mathrm{CaD}$, or between the subgroups based on residential status and baseline dietary calcium intake for total, vertebral or forearm fracture. Fig 1 and table 6 show that there were differences in all subgroup analyses for hip fracture, which were largely because of the results of a single large trial of CaD with a $23 \%$ reduction in hip fractures that was carried out in women living in residential care with a low dietary calcium intake and low vitamin D concentrations. ${ }^{1516}$ In all four subgroup analyses (risk of bias, calcium or $\mathrm{CaD}$, residential status, and baseline dietary calcium intake), whichever subgroup this study was in had markedly different results to the other subgroup, in which there were non-significant increases in risk of hip fracture.

Table 7 shows the results of the sensitivity analyses. Inclusion of two randomised controlled trials at high risk of bias ${ }^{1314}$ and analysis of one cluster randomised controlled trial ${ }^{1516}$ as an individually randomised trial did not alter the results. We used the result from the reanalysis of the Women's Health Initiative restricting participants to those not using oestrogen (relative risk 1.20, 95\% confidence interval 0.85 to 1.69$)^{19}$ instead of the result for the entire cohort $(0.88,0.72$ to 1.07$) .{ }^{9}$ This had a modest effect, moving the results toward those of the trials at low risk of bias. We repeated our analyses excluding the influential trial with the outlying results. ${ }^{15} 16$ The relative risk was 0.90 (0.82 to 0.98$)$ for total fracture and 1.02 (0.78 to 1.34) for hip fracture. 


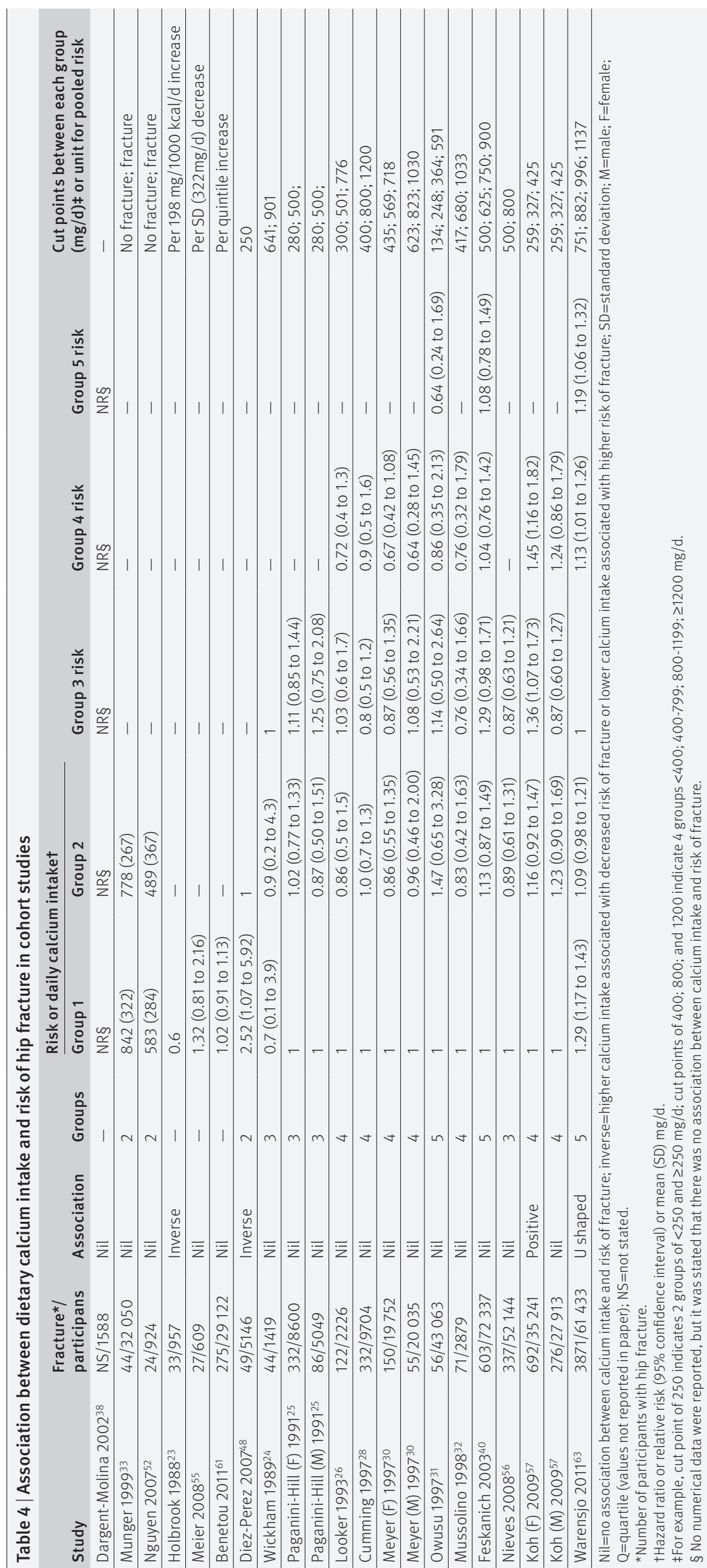

\section{Cohort studies}

Table 2 and table $\mathrm{C}$ in appendix 3 show the study design and selected characteristics of the 11 cohort studies that reported associations between calcium supplements and fracture outcomes. Most studies reported no association between calcium use and fracture (table $\mathrm{F}$ in appendix 3). Of the 20 reported associations, 13 were neutral, five were positive, and two were inverse.

\section{Discussion}

There is insufficient evidence to assess the effect of increasing calcium intake in the diet from randomised controlled trials as only two small trials of dietary sources of calcium have reported fracture outcomes. Some 42 cohort studies, however, have assessed relation between dietary calcium intake, milk or dairy intake and fracture. Most analyses ( $\geq 75 \%$ ) found no associations, and where there were relations reported, most relative risks were between 0.5 and 2.0, which are considered weak associations in observational studies. ${ }^{72}$ The recommended dietary calcium intake for older adults is $1200 \mathrm{mg} /$ day. ${ }^{1}$ Most studies, however, did not report reduced risk of fracture in individuals with this level of calcium intake compared with lower intakes. Thus, observational research does not support a hypothesis of dietary "calcium deficiency" in which there are reductions in fracture risk from increasing dietary calcium intake across the range of intakes $(<300->1200 \mathrm{mg} /$ day $)$ in studies in this review.

In 26 randomised controlled trials, calcium supplements reduced the risk of total fracture by $11 \%$ and vertebral fracture by $14 \%$ but had no effect on forearm or hip fracture. The results, however, were not consistent. There was no effect of calcium supplements on any fracture outcome in the largest trials at lowest risk of bias. Only one trial in frail elderly women in residential care with low dietary calcium intake and vitamin D concentrations showed significant reductions in fracture risk. Funnel plots were also asymmetric with more small-moderate sized studies than expected reporting risk reductions in total, vertebral, and forearm fracture with calcium supplements, raising the possibility of publication bias. Results from randomised controlled trials of calcium monotherapy were similar to those with $\mathrm{CaD}$, with no evidence of additional benefit of vitamin D on risk. These results suggest that widespread untargeted use of calcium supplements in older individuals is unlikely to result in meaningful reductions in incidence of fracture.

\section{Strengths and limitations}

The strength of this review is its comprehensive nature, including both randomised controlled trials and observational studies, and assessment of four fracture outcomes: total, hip, vertebral, and forearm. An important limitation is the difficulty of identifying all cohort studies that reported relations between calcium intake and fracture risk. Many of the reports of cohort studies included in our review were not 


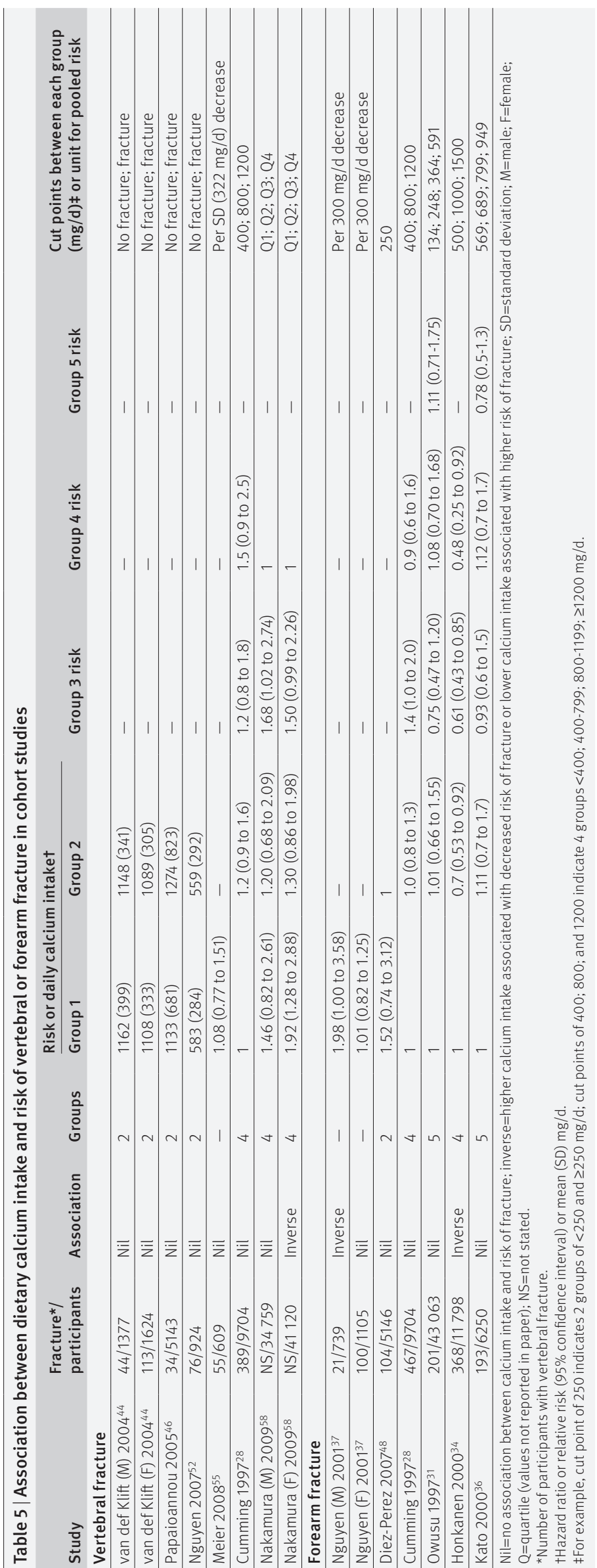

identified by the database searches because the relation between calcium intake and fracture was not the focus of the report, with the results reported in the text or tables of the article but not the abstract. This was more likely to occur when there was no association between calcium intake and fracture, so the current analysis might overestimate the relation between diet and fracture. We did not perform a quality assessment of the cohort studies, although we included only those studies with a prospective cohort design, considered to be the strongest observational methods.

Generally, observational studies are considered to have a higher risk of bias than large well conducted randomised controlled trials. Tools for assessing quality of observational studies are available, but they often focus on reporting of studies rather than topic specific issues, such as methods of assessment of dietary calcium intake, methods of fracture assessment, categorisation of dietary calcium intake in statistical models, and inclusion of covariates in those models. Such factors are likely to be extremely influential in the results of the cohort studies but are either not easily assessed or not able to be assessed. If we limited our results to cohort studies with more than 100 fractures in which fracture risk by baseline dietary calcium intake was reported for at least three groups, most studies reported no association between baseline dietary calcium and fracture (5/7 for total fracture, 6/8 for hip fracture, 1/1 for vertebral fracture, and 3/4 for forearm fracture). The results from these large studies are similar to the overall results, and each study has adequate power to detect clinically relevant effect sizes.

We did not perform meta-regression analyses because there were few studies that reported sufficient data for such an analysis. Individual patient data analyses might be of value in further exploring the relation between baseline calcium intake and fracture risk. Other important limitations include that many of the randomised controlled trials were of short duration and did not have fracture as the primary endpoint. The trials were generally carried out in healthy populations or those at risk of osteoporosis, and so the findings might not apply to other population groups.

\section{Results in context}

Overall, there is little evidence currently to suggest an association between calcium intake and fracture risk or that increasing calcium intake through dietary sources will alter risk. Although calcium supplements produced some small inconsistent reductions in fractures, the doses used of 500-1600 mg/day gave an average total daily calcium intake of $1780 \mathrm{mg} /$ day (range 1230-2314 $\mathrm{mg} /$ day). This is considerably higher than the dietary calcium intake in the highest quarter or fifth in the prospective observational studies. If calcium supplements are correcting dietary "calcium deficiency" it might be necessary to increase dietary calcium intake to about $1800 \mathrm{mg} /$ day to achieve equivalent effects to calcium 


\begin{tabular}{|c|c|c|}
\hline \multirow[b]{2}{*}{ Study } & \multicolumn{2}{|c|}{ No of events/total } \\
\hline & Calcium & Control \\
\hline \multicolumn{3}{|l|}{ Low risk of bias } \\
\hline Grant 2005 & $364 / 2617$ & $400 / 2675$ \\
\hline Jackson 2006 & 2102/18 176 & $2158 / 18106$ \\
\hline Prince 2006 & $110 / 730$ & $126 / 730$ \\
\hline Reid 2006 & $134 / 732$ & $147 / 739$ \\
\hline Total $(95 \% \mathrm{Cl})$ & $2710 / 22255$ & $2831 / 22250$ \\
\hline \multicolumn{3}{|c|}{ Test for heterogeneity: $P=0.77, I^{2}=0 \%$} \\
\hline \multicolumn{3}{|l|}{ Moderate risk of bias } \\
\hline Reid 1993 & $6 / 68$ & $10 / 67$ \\
\hline Chapuy 1994 & $240 / 1537$ & 290/1539 \\
\hline Chevalley 1994 & $2 / 62$ & $2 / 31$ \\
\hline Riggs 1998 & $11 / 119$ & $12 / 117$ \\
\hline Baron 1999 & $4 / 464$ & $14 / 466$ \\
\hline Porthouse 2005 & $58 / 1321$ & $91 / 1993$ \\
\hline Reid 2008 & $9 / 216$ & $8 / 107$ \\
\hline Salovaara 2010 & $78 / 1718$ & $94 / 1714$ \\
\hline Total $(95 \% \mathrm{Cl})$ & $408 / 5505$ & $521 / 6034$ \\
\hline \multicolumn{3}{|c|}{ Test for heterogeneity: $P=0.56, \mathrm{I}^{2}=0 \%$} \\
\hline \multicolumn{3}{|l|}{ High risk of bias } \\
\hline Dawson-Hughes 1997 & $11 / 187$ & $26 / 202$ \\
\hline Peacock 2000 & $11 / 126$ & $10 / 135$ \\
\hline Chapuy 2002 & $69 / 389$ & $34 / 194$ \\
\hline Avenell 2004 & $9 / 64$ & $8 / 70$ \\
\hline Harwood 2004 & $6 / 75$ & $5 / 75$ \\
\hline Bolton-Smith 2007 & $2 / 62$ & $2 / 61$ \\
\hline Bonnick 2007 & $9 / 282$ & $28 / 281$ \\
\hline Sambrook 2012 & $11 / 170$ & $14 / 156$ \\
\hline Total $(95 \% \mathrm{Cl})$ & $128 / 1355$ & $127 / 1174$ \\
\hline \multicolumn{3}{|c|}{ Test for heterogeneity: $\mathrm{P}=0.08, \mathrm{I}^{2}=44 \%$} \\
\hline \multicolumn{3}{|c|}{ Test for heterogeneity between subgroups: $\mathrm{P}=0.05$} \\
\hline All studies & $3246 / 29115$ & $3479 / 29458$ \\
\hline \multicolumn{3}{|l|}{ Overall: $\mathrm{P}=0.004$} \\
\hline Test for heterogeneity: & $17, I^{2}=27 \%$ & \\
\hline
\end{tabular}

Fig 1 Random effects models of effect of calcium supplements on risk of total fracture. Trials with no events are not included in meta-analyses

supplements. Dietary manipulation to increase calcium intake by $\geq 1000 \mathrm{mg} /$ day or to achieve total daily intakes of this size is unlikely to be sustainable.

The pooled analyses of all randomised controlled trials showed reductions in risk with calcium supplements for all fractures (by 11\%) and vertebral fractures (by 14\%). The incidence of vertebral fracture and any fracture in the control groups in our pooled analyses was $1.5 \%$ and $12 \%$, respectively, after a participant weighted average duration of follow-up of 6.2 and 5.5 years, respectively. With these values and the observed risk reductions from the meta-analyses, the number needed to treat (NNT) with calcium to prevent one vertebral fracture is 489 for 6.2 years and to prevent one fracture at any site is 77 for 5.5 years. These benefits are unlikely to be attractive for an individual and would be even smaller for individuals at lower risk of fracture, who are often advised to take calcium supplements, or if relative risks from the randomised controlled trials at lowest risk of bias were used in the calculations. There was no benefit from calcium sup- plements for hip fractures, which have the greatest clinical consequences.

Small benefits might be useful at a population level if calcium supplements were used widely, well tolerated, and safe. Persistence with calcium supplements in clinical trials is low, however, at about 40-60\%,9878990 and in one recent randomised controlled trial, there were 24 more women admitted to hospital for acute gastrointestinal symptoms in the calcium group than the placebo group, and 16 fewer women with a fracture. ${ }^{10} 89$ In another randomised controlled trial, there were 68 more women with a kidney stone in the $\mathrm{CaD}$ group and 56 fewer women with a fracture. ${ }^{9}$ In our randomised controlled trial and subsequent meta-analyses, the cardiovascular risks of calcium were similar to $0^{67}$ or exceeded ${ }^{8}$ the benefits of calcium on fracture prevention. In addition, $10-20 \%$ of people experience gastrointestinal side effects such as constipation, which cause a considerable number to stop taking the supplements. Thus, because of the small benefits of use and unfavourable risk:benefit 


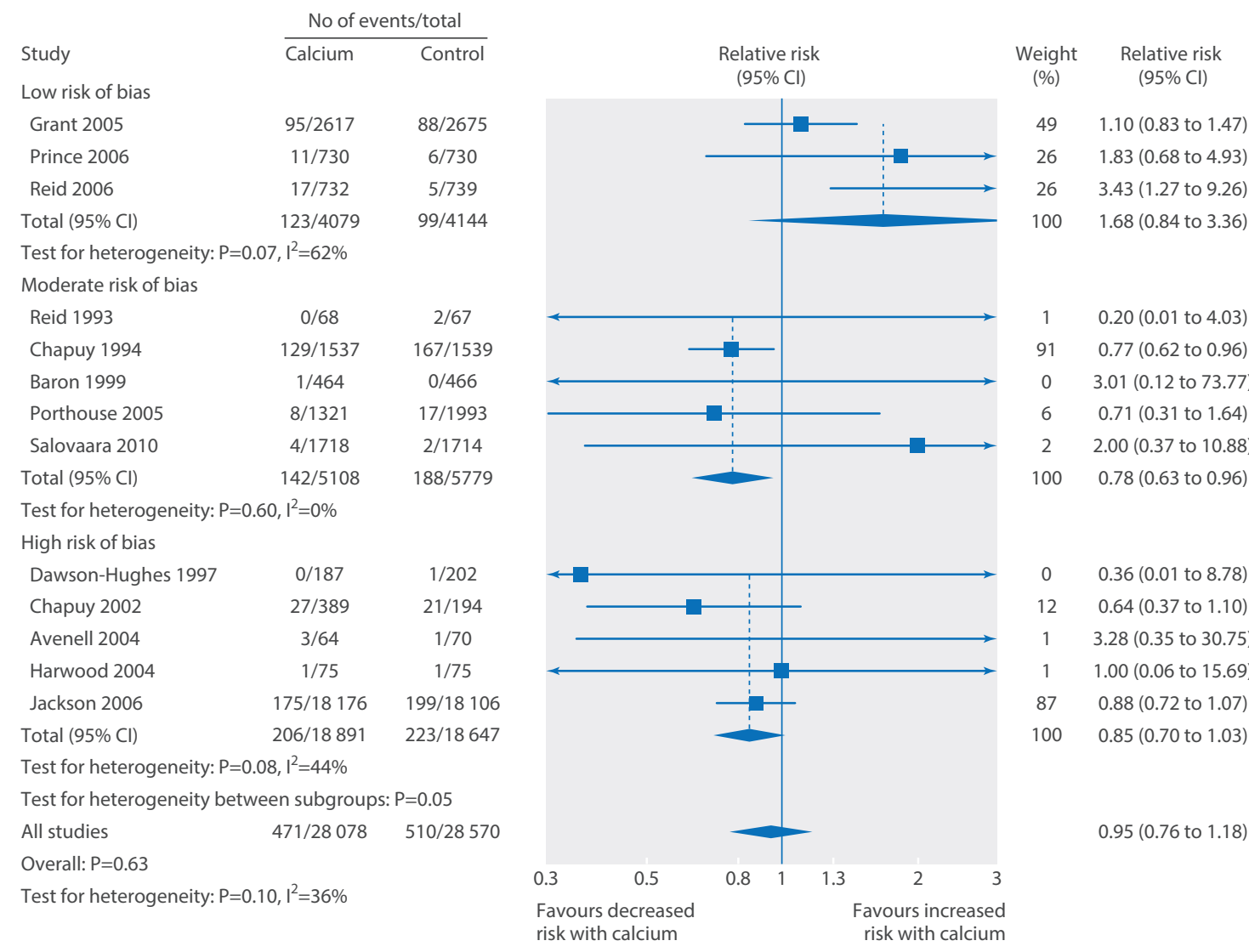

Fig 2 Random effects models of effect of calcium supplements on risk of hip fracture. Trials with no events are not included in meta-analyses

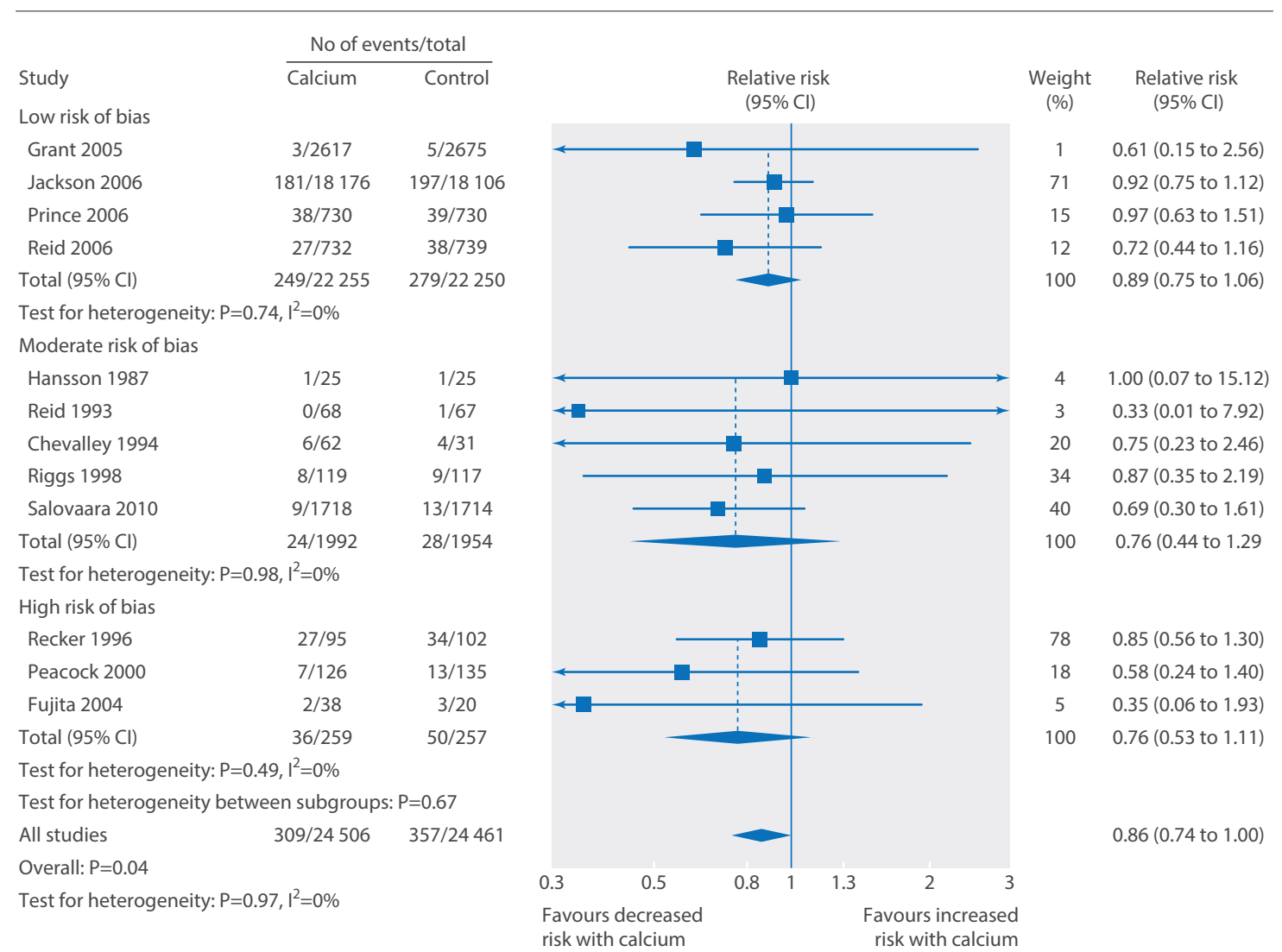

Fig 3 | Random effects models of effect of calcium supplements on risk of vertebral fracture. Trials with no events are not included in meta-analyses 


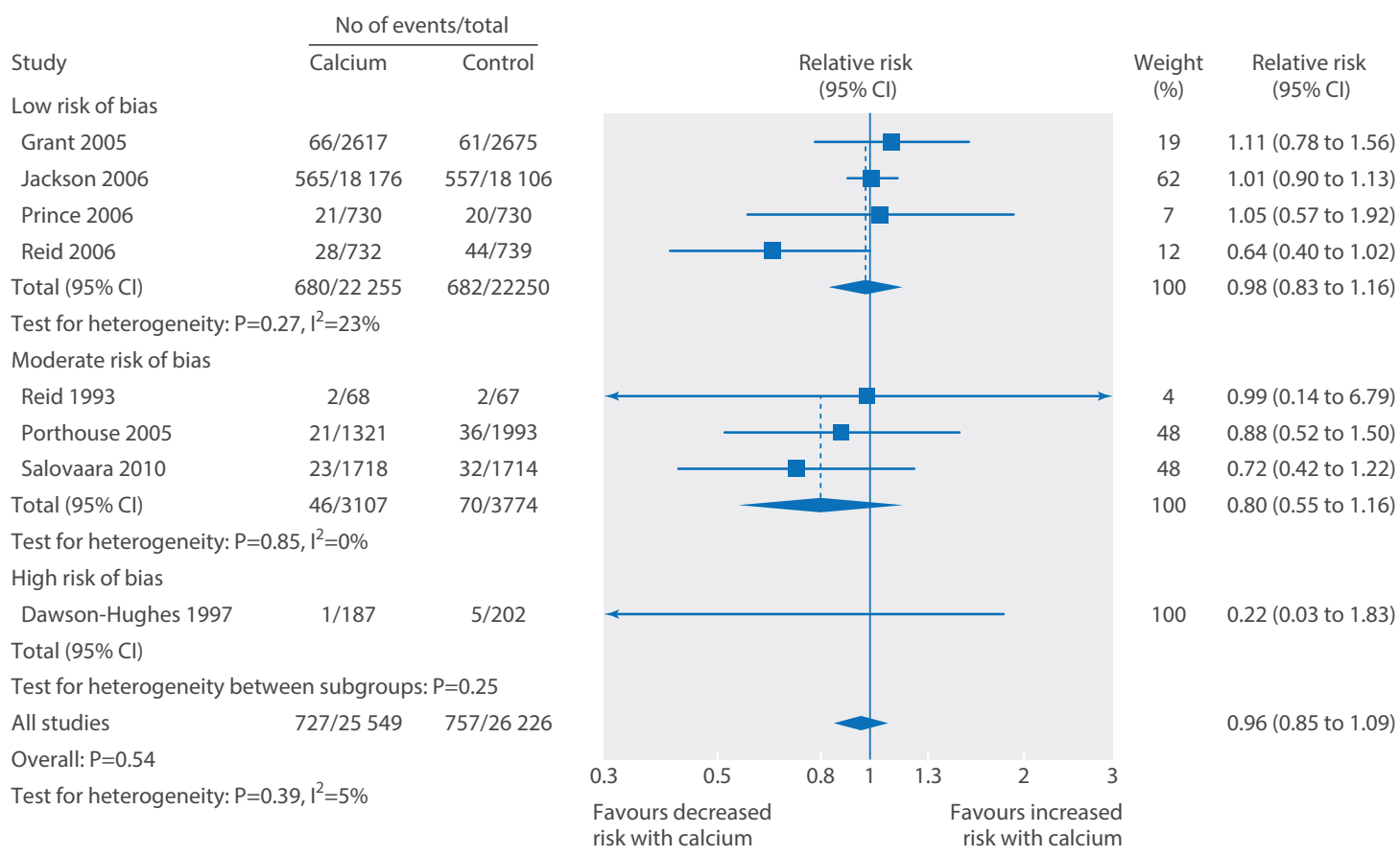

Fig 4 | Random effects models of effect of calcium supplements on risk of forearm hip fracture. Trials with no events are not included in meta-analyses

profile, calcium supplements should not be recommended for fracture prevention either at an individual or population level.

An important point emerging from our analyses is the impact of one randomised controlled trial ${ }^{15}$ on previous meta-analyses. Chapuy and colleagues studied frail elderly French women (mean age 84) in residential care with low baseline dietary calcium intake (513 mg/day) and low baseline vitamin D concentrations (mean about $20 \mathrm{nmol} / \mathrm{L}$ in modern assays $\left.^{83}\right)$. Of these participants, $16 \%$ died within 18 months of randomisation. Co-administered $\mathrm{CaD}$ $(1200 \mathrm{mg} /$ day, $800 \mathrm{IU} /$ day) reduced hip fractures by $23 \%$ and all fractures by $17 \%$ at three years. ${ }^{16}$ These results are in contrast to all six other large randomised controlled trials $(\mathrm{n}>1000)$ of calcium or $\mathrm{CaD}$, none of which reported significant reductions in total or hip fracture risk (fig 1). Based on the average vitamin D concentrations in the Chapuy study (about 20 $\mathrm{nmol} / \mathrm{L}$ ), it is possible that many participants had unrecognised osteomalacia, the treatment of which might have led to the benefits observed. Therefore, the benefits of $\mathrm{CaD}$ in this study should not be expected to be reproduced in cohorts with higher vitamin D concentrations. In our subgroup analyses, whichever subgroup the Chapuy study was in had reductions in risk of hip fracture that were markedly different to the other subgroup (table 7). The influence of this single trial is also a feature of previous meta-analyses that concluded that high dose but not low dose vitamin D prevents fractures, ${ }^{95}$ co-administered CaD but not vitamin $\mathrm{D}$ prevents fractures, ${ }^{96}$ and CaD administered to people living in residential care but not in the community prevents fractures. ${ }^{17}$ Our analyses highlight that the results from this study of a frail population with marked vitamin D deficiency are so different to those from other large randomised controlled trials and so influential in any pooled analysis that they should probably not be combined in pooled analyses with studies that enrolled different patient groups. Furthermore, recommendation of use of calcium and vitamin D supplements generally for older adults to prevent fracture based on results heavily influenced by this study of frail women in residential care is inappropriate.

On the basis of the trial data summarised here, we do not think further randomised controlled trials of calcium supplements with or without vitamin D with fracture as the endpoint in the general population are needed. In the population of frail elderly women with low dietary calcium intake and low vitamin D concentrations studied by Chapuy and colleagues, ${ }^{15}$ co-administered $\mathrm{CaD}$ was clearly beneficial. Important adverse events such as cardiovascular events, however, were not reported, and it remains uncertain whether the benefit was due to vitamin $\mathrm{D}$ or calcium or both. Trials to compare the effects of $\mathrm{CaD}$ with vitamin D monotherapy in this population group and also to assess whether reduction in fracture risk with anti-resorptive agents requires co-administration of either vitamin $\mathrm{D}$ or $\mathrm{CaD}$ would be valuable. Surrogate endpoints, such as bone mineral density, allow biological effects of agents to be assessed in much smaller randomised controlled trials. The effects of increasing dietary calcium intake on bone mineral density in the general population and in specific subgroups considered most likely to benefit from this intervention should be examined before large trials with fracture as an endpoint are considered, though it should not be assumed that short term changes in 


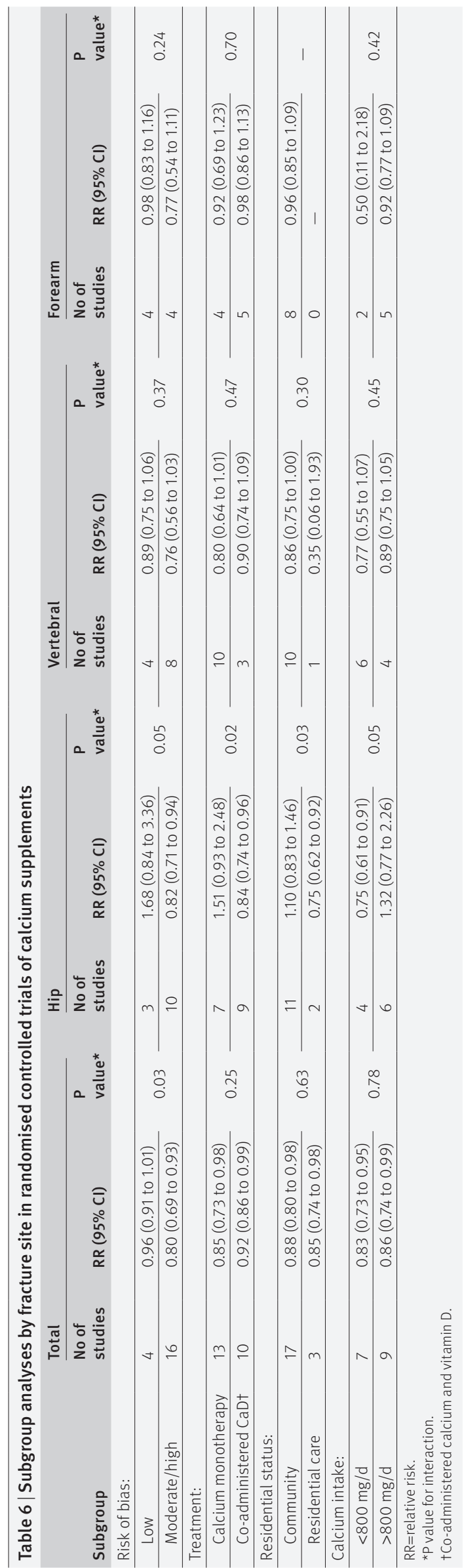

Table 7 | Sensitivity analyses of randomised controlled trials of calcium supplements and risk of fracture

\begin{tabular}{|c|c|c|}
\hline Analysis and fracture site & No of studies & $\begin{array}{l}\text { Relative risk } \\
(95 \% \mathrm{Cl})\end{array}$ \\
\hline \multicolumn{3}{|c|}{ Include Inkovaara $1983^{13}$ and Larsen $2004^{14 *}$} \\
\hline Total fracture & 22 & $0.90(0.83$ to 0.96$)$ \\
\hline \multicolumn{3}{|c|}{ Include Inkovaara $1983^{13}$ and Larsen $2004^{14} \dagger$} \\
\hline Total fracture & 22 & $0.89(0.83$ to 0.95$)$ \\
\hline \multicolumn{3}{|c|}{ Analyse Chapuy $1994^{1516}$ as individually randomised } \\
\hline Total fracture & 20 & $0.88(0.81$ to 0.96$)$ \\
\hline Hip fracture & 13 & 0.95 (0.76 to 1.18$)$ \\
\hline \multicolumn{3}{|c|}{ Restrict Jackson $2006^{9}$ to women not using oestrogen ${ }^{19}$} \\
\hline Hip fracture-all studies & 13 & $1.04(0.80$ to 1.34$)$ \\
\hline Hip fracture-CaD subgroup & 9 & $0.90(0.75$ to 1.08$)$ \\
\hline $\begin{array}{l}\text { Hip fracture-community } \\
\text { dwelling }\end{array}$ & 11 & 1.20 (0.97 to 1.48$)$ \\
\hline $\begin{array}{l}\text { Hip fracture-calcium } \\
\text { intake }>800 \mathrm{mg} / \mathrm{d}\end{array}$ & 6 & 1.41 (0.92 to 2.18$)$ \\
\hline \multicolumn{3}{|l|}{ Exclude Chapuy $1994^{15} 16$} \\
\hline Total fracture & 19 & $0.90(0.82$ to 0.98$)$ \\
\hline Hip fracture & 12 & $1.02(0.78$ to 1.34$)$ \\
\hline
\end{tabular}

bone density will be sustained or translate into fracture prevention. ${ }^{97}$

\section{Conclusions}

In summary, our analyses indicate that dietary calcium intake is not associated with risk of fracture, and there is no evidence currently that increasing dietary calcium intake prevents fractures. Calcium supplements have small inconsistent benefits on fracture reduction but probably have an unfavourable risk:benefit profile. There was no risk reduction in fracture at any site in pooled analyses of the randomised controlled trials of calcium supplements at lowest risk of bias, and there was evidence of publication bias in small-moderate sized trials. Collectively, these results suggest that clinicians, advocacy organisations, and health policymakers should not recommend increasing calcium intake for fracture prevention, either with calcium supplements or through dietary sources.

Contributors: MIB, WL, AG, and IRR designed the research. WL and MJB performed the literature search. WL, VT, SB, and MJB extracted or checked data. MJB and GDG performed the analyses. MJB drafted the paper. All authors critically reviewed and improved it. MJB is guarantor. All authors had access to all the data and take responsibility for the integrity of the data and the accuracy of the data analysis.

Funding: The study was funded by the Health Research Council (HRC) of New Zealand. MJB is the recipient of a Sir Charles Hercus Health Research Fellowship. The authors are independent of the HRC. The HRC had no role in study design, the collection, analysis, and interpretation of data, the writing of the article, or the decision to submit it for publication.

Competing interests: All authors have completed the ICMIE uniform disclosure form at www.icmje.org/coi_disclosure.pdf and declare: the study was funded by the Health Research Council (HRC) of New

Zealand. MJB is the recipient of a Sir Charles Hercus Health Research Fellowship; IRR has received research grants and/or honorariums from Merck, Amgen, Lilly, and Novartis; all other authors have no financial relationships with any organisations that might have an interest in the submitted work in the previous three years; no other relationships or activities that could appear to have influenced the submitted work.

Ethical approval: Not required. 
Transparency statement: MB affirms that the manuscript is an honest, accurate, and transparent account of the study being reported; that no important aspects of the study have been omitted; and that any discrepancies from the study as planned have been explained Data sharing: No additional data available.

This is an Open Access article distributed in accordance with the Creative Commons Attribution Non Commercial (CC BY-NC 4.0) license, which permits others to distribute, remix, adapt, build upon this work non-commercially, and license their derivative works on different terms, provided the original work is properly cited and the use is noncommercial. See: http://creativecommons.org/licenses/by-nc/4.0/.

1 IOM (Institute of Medicine). Dietary reference intakes for calcium and vitamin D. National Academies Press, 2011

2 Bailey RL, Dodd KW, Goldman JA, et al. Estimation of total usual calcium and vitamin D intakes in the United States. J Nutr 2010;140:817-22

3 Anderson JJ, Roggenkamp KJ, Suchindran CM. Calcium intakes and femoral and lumbar bone density of elderly U.S. men and women: National Health and Nutrition Examination Survey 2005-2006 analysis. J Clin Endocrinol Metab 2012;97:4531-9.

4 Castro-Lionard K, Dargent-Molina P, Fermanian C, Gonthier R, Cassou B. Use of calcium supplements, vitamin D supplements and specific osteoporosis drugs among French women aged $75-85$ years: patterns of use and associated factors. Drugs Aging 2013;30:1029-38.

5 Xiao Q, Murphy RA, Houston DK, Harris TB, Chow WH, Park Y. Dietary and supplemental calcium intake and cardiovascular disease mortality: the National Institutes of Health-AARP diet and health study. JAMA Intern Med 2013;173:639-46.

6 Bolland MJ, Barber PA, Doughty RN, Mason B, Horne A, Ames R, et al. Vascular events in healthy older women receiving calcium supplementation: randomised controlled trial. BM/ 2008;336:262-6.

7 Bolland MJ, Avenell A, Baron JA, Grey A, Maclennan GS, Gamble GD, et al. Effect of calcium supplements on risk of myocardial infarction and cardiovascular events: meta-analysis. BMJ 2010;341:c3691.

8 Bolland MJ, Grey A, Avenell A, Gamble GD, Reid IR. Calcium supplements with or without vitamin D and risk of cardiovascular events: reanalysis of the Women's Health Initiative limited access dataset and meta-analysis. BMJ 2011;342:d2040.

9 Jackson RD, LaCroix AZ, Gass M, Wallace RB, Robbins J, Lewis CE, et al. Calcium plus vitamin D supplementation and the risk of fractures. N Engl J Med 2006;354:669-83.

10 Lewis JR, Zhu K, Prince RL. Adverse events from calcium supplementation: relationship to errors in myocardial infarction self-reporting in randomized controlled trials of calcium supplementation. J Bone Miner Res 2012;27:719-22.

11 Bauer DC. Clinical practice. Calcium supplements and fracture prevention. N Engl J Med 2013;369:1537-43.

12 Higgins JPT, Green S, eds. Cochrane handbook for systematic reviews of interventions, version 5.1.0. Cochrane Collaboration, 2011. www. cochrane-handbook.org.

13 Inkovaara J, Gothoni G, Halttula R, Heikinheimo R, Tokola O. Calcium, vitamin $\mathrm{D}$ and anabolic steroid in treatment of aged bones: double-blind placebo-controlled long-term clinical trial. Age Ageing 1983;12:124-30

14 Larsen ER, Mosekilde L, Foldspang A. Vitamin D and calcium supplementation prevents osteoporotic fractures in elderly community dwelling residents: a pragmatic population-based 3-year intervention study. J Bone Miner Res 2004;19:370-8.

15 Chapuy MC, Arlot ME, Duboeuf F, et al. Vitamin D3 and calcium to prevent hip fractures in the elderly women. N Engl I Med 1992;327:1637-42

16 Chapuy MC, Arlot ME, Delmas PD, Meunier PJ. Effect of calcium and cholecalciferol treatment for three years on hip fractures in elderly women. BM/ 1994:308:1081-2.

17 Avenell A, Gillespie WJ, Gillespie LD, O'Connell D. Vitamin D and vitamin $D$ analogues for preventing fractures associated with involutional and post-menopausal osteoporosis. Cochrane Database Syst Rev 2009:2;CD000227.

18 Sambrook PN, Cameron ID, Chen JS, et al. Does increased sunlight exposure work as a strategy to improve vitamin D status in the elderly: a cluster randomised controlled trial. Osteoporos Int 2012;23:615-24.

19 Robbins JA, Aragaki A, Crandall CJ, et al. Women's Health Initiative clinical trials: interaction of calcium and vitamin D with hormone therapy. Menopause 2014;21:116-23.

20 Lau EM, Woo J, Lam V, Hong A. Milk supplementation of the diet of postmenopausal Chinese women on a low calcium intake retards bone loss. J Bone Miner Res 2001;16:1704-9.

21 Chevalley T, Rizzoli R, Nydegger V, et al. Effects of calcium supplements on femoral bone mineral density and vertebral fracture rate in vitamin-D-replete elderly patients. Osteoporos Int 1994;4:245-52

22 Riggs BL, Seeman E, Hodgson SF, Taves DR, O'Fallon WM. Effect of the fluoride/calcium regimen on vertebral fracture occurrence in postmenopausal osteoporosis. Comparison with conventional therapy. N Engl I Med 1982;306:446-50.
23 Holbrook TL, Barrett-Connor E, Wingard DL. Dietary calcium and risk of hip fracture: 14-year prospective population study. Lancet 1988;2:1046-9.

24 Wickham CA, Walsh K, Cooper C, et al. Dietary calcium, physical activity, and risk of hip fracture: a prospective study. BMJ 1989;299:889-92

25 Paganini-Hill A, Chao A, Ross RK, Henderson BE. Exercise and other factors in the prevention of hip fracture: the Leisure World study. Epidemiology 1991;2:16-25.

26 Looker AC, Harris TB, Madans JH, Sempos CT. Dietary calcium and hip fracture risk: the NHANES I Epidemiologic Follow-Up Study. Osteoporos Int 1993;3:177-84.

27 Huang Z, Himes JH, McGovern PG. Nutrition and subsequent hip fracture risk among a national cohort of white women. Am J Epidemiol 1996;144:124-34.

28 Cumming RG, Cummings SR, Nevitt MC, et al. Calcium intake and fracture risk: results from the study of osteoporotic fractures. Am J Epidemiol 1997;145:926-34

29 Fujiwara S, Kasagi F, Yamada M, Kodama K. Risk factors for hip fracture in a Japanese cohort. J Bone Miner Res 1997;12:998-1004.

30 Meyer HE, Pedersen II, Loken EB, Tverdal A. Dietary factors and the incidence of hip fracture in middle-aged Norwegians. A prospective study. Am J Epidemiol 1997;145:117-23.

31 Owusu W, Willett WC, Feskanich D, Ascherio A, Spiegelman D, Colditz GA. Calcium intake and the incidence of forearm and hip fractures among men. J Nutr 1997;127:1782-7.

32 Mussolino ME, Looker AC, Madans JH, Langlois JA, Orwoll ES. Risk factors for hip fracture in white men: the NHANES I epidemiologic follow-up study. J Bone Miner Res 1998;13:918-24.

33 Munger RG, Cerhan JR, Chiu BC. Prospective study of dietary protein intake and risk of hip fracture in postmenopausal women. Am I Clin Nutr 1999;69:147-52.

34 Honkanen RJ, Honkanen K, Kroger H, Alhava E, Tuppurainen M, Saarikoski S. Risk factors for perimenopausal distal forearm fracture. Osteoporos Int 2000;11:265-70

35 Huopio J, Kroger H, Honkanen R, Saarikoski S, Alhava E. Risk factors for perimenopausal fractures: a prospective study. Osteoporos Int 2000;11:219-27.

36 Kato I, Toniolo P, Zeleniuch-Jacquotte A, et al. Diet, smoking and anthropometric indices and postmenopausal bone fractures: a prospective study. Int J Epidemiol 2000;29:85-92.

37 Nguyen TV, Center JR, Sambrook PN, Eisman JA. Risk factors for proximal humerus, forearm, and wrist fractures in elderly men and women: the Dubbo osteoporosis epidemiology study. Am J Epidemiol 2001;153:587-95.

38 Dargent-Molina P, Douchin MN, Cormier C, Meunier PJ, Breart G, Group ES. Use of clinical risk factors in elderly women with low bone mineral density to identify women at higher risk of hip fracture: the EPIDOS prospective study. Osteoporos Int 2002;13:593-9.

39 Albrand G, Munoz F, Sornay-Rendu E, DuBoeuf F, Delmas PD. Independent predictors of all osteoporosis-related fractures in healthy postmenopausal women: the OFELY study. Bone 2003;32:78-85.

40 Feskanich D, Willett WC, Colditz GA. Calcium, vitamin D, milk consumption, and hip fractures: a prospective study among postmenopausal women. Am J Clin Nutr 2003;77:504-11.

41 Michaelsson K, Melhus H, Bellocco R, Wolk A. Dietary calcium and vitamin $\mathrm{D}$ intake in relation to osteoporotic fracture risk. Bone 2003;32:694-703

42 Melton LJ 3rd, Crowson CS, O’Fallon WM, Wahner HW, Riggs BL. Relative contributions of bone density, bone turnover, and clinical risk factors to long-term fracture prediction. J Bone Miner Res 2003;18:312-8.

43 Roy DK, O’Neill TW, Finn JD, et al. Determinants of incident vertebral fracture in men and women: results from the European prospective osteoporosis study (EPOS). Osteoporos Int 2003;14:19-26.

44 Van der Klift M, de Laet CE, McCloskey EV, et al. Risk factors for incident vertebral fractures in men and women: the Rotterdam study. J Bone Miner Res 2004;19:1172-80.

45 Kanis JA, Johansson $\mathrm{H}$, Oden A, et al. A meta-analysis of milk intake and fracture risk: low utility for case finding. Osteoporos Int 2005; 16:799-804.

46 Papaioannou A, Joseph L, loannidis G, et al. Risk factors associated with incident clinical vertebral and nonvertebral fractures in postmenopausal women: the Canadian multicentre osteoporosis study (CaMos). Osteoporos Int 2005;16:568-78.

47 Cauley JA, Wu L, Wampler NS, et al. Clinical risk factors for fractures in multi-ethnic women: the Women's Health Initiative. J Bone Miner Res 2007:22:1816-26.

48 Diez-Perez A, Gonzalez-Macias J, Marin F, et al. Prediction of absolute risk of non-spinal fractures using clinical risk factors and heel quantitative ultrasound. Osteoporos Int 2007;18:629-39.

49 Key TJ, Appleby PN, Spencer EA, Roddam AW, Neale RE, Allen NE. Calcium, diet and fracture risk: a prospective study of 1898 incident fractures among 34696 British women and men. Public Health Nutr 2007;10:1314-20. 
50 Kung AW, Lee KK, Ho AY, Tang G, Luk KD. Ten-year risk of osteoporotic fractures in postmenopausal Chinese women according to clinical risk factors and BMD T-scores: a prospective study. J Bone Miner Res 2007;22:1080-7

51 Lewis CE, Ewing SK, Taylor BC, et al. Predictors of non-spine fracture in elderly men: the MrOS study. J Bone Miner Res 2007;22:211-9.

52 Nguyen ND, Eisman JA, Center JR, Nguyen TV. Risk factors for fracture in nonosteoporotic men and women. J Clin Endocrinol Metab 2007;92:955-62.

53 Van Geel TACM, Geusens PP, Nagtzaam IF, et al. Risk factors for clinical fractures among postmenopausal women: a 10-year prospective study. Menopause Int 2007;13:110-5

54 Dargent-Molina P, Sabia S, Touvier M, et al. Proteins, dietary acid load, and calcium and risk of postmenopausal fractures in the E3N French women prospective study. J Bone Miner Res 2008;23:1915-22.

55 Meier C, Nguyen TV, Handelsman DJ, et al. Endogenous sex hormones and incident fracture risk in older men: the Dubbo osteoporosis epidemiology Study. Arch Intern Med 2008;168:47-54.

56 Nieves JW, Barrett-Connor E, Siris ES, Zion M, Barlas S, Chen YT. Calcium and vitamin D intake influence bone mass, but not short-term fracture risk, in caucasian postmenopausal women from the national osteoporosis risk assessment (NORA) study. Osteoporos Int 2008;19:673-9.

57 Koh WP, Wu AH, Wang R, et al. Gender-specific associations between soy and risk of hip fracture in the Singapore Chinese health study. Am J Epidemiol 2009;170:901-9.

58 Nakamura K, Kurahashi N, Ishihara J, Inoue M, Tsugane S, Japan Public Health Centre-based Prospective Study G. Calcium intake and the 10 -year incidence of self-reported vertebral fractures in women and men: the Japan public health centre-based prospective study. $\mathrm{Br}$ J Nutr 2009;101:285-94

59 Thomas-John M, Codd MB, Manne S, Watts NB, Mongey AB. Risk factors for the development of osteoporosis and osteoporotic fractures among older men. / Rheumatol 2009:36:1947-52

60 Gronskag AB, Forsmo S, Romundstad P, Langhammer A, Schei B. Dairy products and hip fracture risk among elderly women in Norway-the Hunt study. Osteoporos Int 2010;21:S94-5.

61 Benetou V, Orfanos P, Zylis D, et al. Diet and hip fractures among elderly Europeans in the EPIC cohort. Eur J Clin Nutr 2011;65:132-9.

62 Nakamura K, Saito T, Oyama M, et al. Vitamin D sufficiency is associated with low incidence of limb and vertebral fractures in community-dwelling elderly Japanese women: the Muramatsu study. Osteoporos Int 2011;22:97-103.

63 Warensjo E, Byberg L, Melhus H, et al. Dietary calcium intake and risk of fracture and osteoporosis: prospective longitudinal cohort study. BMJ 2011;342:d1473.

64 Khan B, English D, Nowson C, Daly R, Ebeling P. Associations of long-term dietary calcium intake with fractures, cardiovascular events and aortic calcification in a population-based, prospective cohort study. J Bone Miner Res 2012;27.

65 Rouzi AA, Al-Sibiani SA, Al-Senani NS, Radaddi RM, Ardawi MS. Independent predictors of all osteoporosis-related fractures among healthy Saudi postmenopausal women: the CEOR Study. Bone 2012:50:713-22

66 Feart C, Lorrain S, Ginder Coupez V, et al. Adherence to a Mediterranean diet and risk of fractures in French older persons. Osteoporos Int 2013;24:3031-41.

67 Prentice RL, Pettinger MB, Jackson RD, et al. Health risks and benefits from calcium and vitamin D supplementation: Women's Health Initiative clinical trial and cohort study. Osteoporos Int 2013;24:567-80.

68 Samieri C, Ginder Coupez V, Lorrain S, et al. Nutrient patterns and risk of fracture in older subjects: results from the Three-City Study. Osteoporos Int 2013;24:1295-305.

69 Sahni S, Tucker KL, Kiel DP, Quach L, Casey VA, Hannan MT. Milk and yogurt consumption are linked with higher bone mineral density but not with hip fracture: the Framingham offspring study. Arch Osteoporos 2013;8:119.

70 Domiciano DS, Machado LG, Lopes JB, et al Incidence and risk factors for osteoporotic vertebral fracture in low-income community-dwelling elderly: a population-based prospective cohort study in Brazil. The Sao Paulo ageing and health (SPAH) study. Osteoporos Int 2014

71 Sahni S, Mangano KM, Tucker KL, Kiel DP, Casey VA, Hannan MT. Protective association of milk intake on the risk of hip fracture: results from the Framingham original cohort. J Bone Miner Res 2014;29:1756-62.

72 Grimes DA, Schulz KF. False alarms and pseudo-epidemics: the limitations of observational epidemiology. Obstet Gynecol 2012;120:920-7.

73 Hansson T, Roos B. The effect of fluoride and calcium on spinal bone mineral content: a controlled, prospective (3 years) study. Calcif Tissue Int 1987:40:315-7.

74 Reid IR, Ames RW, Evans MC, Gamble GD, Sharpe SJ. Effect of calcium supplementation on bone loss in postmenopausal women. N Engl) Med 1993;328:460-4

75 Reid IR, Ames RW, Evans MC, Gamble GD, Sharpe SJ. Long-term effects of calcium supplementation on bone loss and fractures in postmenopausal women: a randomized controlled trial. Am J Med 1995;98:331-5.
76 Recker RR, Hinders S, Davies KM, et al. Correcting calcium nutritional deficiency prevents spine fractures in elderly women. J Bone Miner Res 1996:11:1961-6.

77 Dawson-Hughes B, Harris SS, Krall EA, Dallal GE. Effect of calcium and vitamin $D$ supplementation on bone density in men and women 65 years of age or older. N Engl J Med 1997;337:670-6.

78 Riggs BL, O'Fallon WM, Muhs J, O'Connor MK, Kumar R, Melton LJ, 3rd. Long-term effects of calcium supplementation on serum parathyroid hormone level, bone turnover, and bone loss in elderly women. J Bone Miner Res 1998:13:168-74

79 Baron JA, Beach M, Mandel JS, et al. Calcium supplements for the prevention of colorectal adenomas. Calcium Polyp Prevention Study Group. N Engl J Med 1999;340:101-7.

80 Bischoff-Ferrari HA, Rees JR, Grau MV, Barry E, Gui J, Baron JA. Effect of calcium supplementation on fracture risk: a double-blind randomized controlled trial. Am J Clin Nutr 2008;87:1945-51.

81 Ruml LA, Sakhaee K, Peterson R, Adams-Huet B, Pak CY. The effect of calcium citrate on bone density in the early and mid-postmenopausal period: a randomized placebo-controlled study. Am J Ther 1999;6:303-11.

82 Peacock M, Liu G, Carey M et al. Effect of calcium or $250 \mathrm{H}$ vitamin D dietary supplementation on bone loss at the hip in men and women over the age of 60. J Clin Endocrinol Metab 2000;85:3011-9.

83 Chapuy MC, Pamphile R, Paris E, et al. Combined calcium and vitamin D3 supplementation in elderly women: confirmation of reversal of secondary hyperparathyroidism and hip fracture risk: the Decalyos II study. Osteoporos Int 2002;13:257-64.

84 Avenell A, Grant AM, McGee M, McPherson G, Campbell MK, McGee MA. The effects of an open design on trial participant recruitment, compliance and retention--a randomized controlled trial comparison with a blinded, placebo-controlled design. Clin Trials 2004:1:490-8.

85 Fujita T, Ohue M, Fujii Y, Miyauchi A, Takagi Y. Reappraisal of Katsurag calcium study, a prospective, double-blind, placebo-controlled study of the effect of active absorbable algal calcium (AAACa) on vertebral deformity and fracture. / Bone Miner Metab 2004:22:32-8.

86 Harwood RH, Sahota O, Gaynor K, Masud T, Hosking DJ. A randomised, controlled comparison of different calcium and vitamin D supplementation regimens in elderly women after hip fracture: the Nottingham neck of femur (NONOF) study. Age Ageing 2004;33:45-51

87 Grant AM, Avenell A, Campbell MK, et al. Oral vitamin D3 and calcium for secondary prevention of low-trauma fractures in elderly people (randomised evaluation of calcium or vitamin D, RECORD): a randomised placebo-controlled trial. Lancet 2005;365:1621-8.

88 Porthouse J, Cockayne S, King C, et al. Randomised controlled trial of calcium and supplementation with cholecalciferol (vitamin D3) for prevention of fractures in primary care. BMJ 2005;330:1003.

89 Prince RL, Devine A, Dhaliwal SS, Dick IM. Effects of calcium supplementation on clinical fracture and bone structure: results of a 5-year, double-blind, placebo-controlled trial in elderly women. Arch Intern Med 2006;166:869-75.

90 Reid IR, Mason B, Horne A, et al. Randomized controlled trial of calcium in healthy older women. Am J Med 2006;119:777-85.

91 Bolton-Smith C, McMurdo ME, Paterson CR, et al. Two-year randomized controlled trial of vitamin K1 (phylloquinone) and vitamin D3 plus calcium on the bone health of older women. J Bone Miner Res 2007:22:509-19.

92 Bonnick S, Broy S, Kaiser F, et al. Treatment with alendronate plus calcium, alendronate alone, or calcium alone for postmenopausal low bone mineral density. Curr Med Res Opin 2007;23:1341-9.

93 Reid IR, Ames R, Mason B, et al. Randomized controlled trial of calcium supplementation in healthy, nonosteoporotic, older men. Arch Intern Med 2008;168:2276-82.

94 Salovaara K, Tuppurainen M, Karkkainen M, et al. Effect of vitamin D(3) and calcium on fracture risk in 65- to 71-year-old women: a population-based 3-year randomized, controlled trial-the OSTPRE-FPS. J Bone Miner Res 2010;25:1487-95.

95 Bischoff-Ferrari HA, Willett WC, Wong JB, Giovannucci E, Dietrich T, Dawson-Hughes B. Fracture prevention with vitamin D supplementation: a meta-analysis of randomized controlled trials. JAMA 2005;293:2257-64

96 Boonen S, Lips P, Bouillon R, Bischoff-Ferrari HA, Vanderschueren D, Haentjens P. Need for additional calcium to reduce the risk of hip fracture with vitamin D supplementation: evidence from a comparative metaanalysis of randomized controlled trials. J Clin Endocrinol Metab 2007;92:1415-23.

97 Tai V, Leung W, Grey A, Reid IR, Bolland MJ. Calcium intake and bone mineral density: systematic review and meta-analysis. BM 2015;351:h4183.

(C) BMJ Publishing Group Ltd 2015

Appendix 1: Literature searches and superseded reports of cohort studies

Appendix 2: Flow of articles

Appendix 3: Supplementary tables A-F 